\title{
Phylogenetic Study of GABA Receptors in Human and Rat Species: Evaluation of Family Relationship
}

Zahrasadat Hashemi ${ }^{1}$, Arezou Eshaghabadi ${ }^{2}$, Fatemeh Alipour ${ }^{2}$, Maryam Jafarian ${ }^{2}$, Sayed Mostafa Modarres Mousavi ${ }^{2,3 *}$

${ }^{1}$ School of Medicine, Tehran University of Medical Sciences, Tehran, Iran

${ }^{2}$ Shefa Neuroscience Research Center, Khatam Alanbia Hospital, Tehran, Iran

${ }^{3}$ Department of Nanobiotechnology, Faculty of Biological Sciences, Tarbiat Modares University, Tehran, Iran

\section{ABSTRACT}

Introduction: An effort to establish phylogenetic values for the major gamma-Aminobutyric acid $\mathrm{A}\left(\mathrm{GABA}_{\mathrm{A}}\right)$ receptor subunit mRNAs $\alpha, \beta, \gamma, \delta, \varepsilon, \theta, \pi$ could be improved our knowledge on their classification and function. In addition, the similarities and divergences between different species can be important to determine the function of these receptors. Materials and Methods: After alignment of mRNA complete gene sequences of GABA ${ }_{\mathrm{A}}$ subunits in homosapinse and rattus norvegicus species, the phylogenetic tree were constructed with CLC Main Workbench 5.5 software. Results: The results revealed highly similarities between $\mathrm{GABA}_{\mathrm{A}}$ subunits of homosapience and rattus norvegicus. In addition, these findings illustrated some divergences between $\beta_{1}, \beta_{2}, \beta_{3}, \gamma_{1}, \gamma_{2}, \varepsilon$ and $\theta$ subunits with other subunits. Conclusion: The similarities and divergences among various $\mathrm{GABA}_{\mathrm{A}}$ subunits may be an important cause of different distribution and function of $\mathrm{GABA}_{\mathrm{A}}$ subunits in different region of the central nervous system.

\section{Key words:}

1. gamma-Aminobutyric Acid

2. Family Relations

3. Brain

*Corresponding Author: Sayed Mostafa Modarres Mousavi

E-mail: modarres.mousavi@gmail.com 
مطالعة فيلوزنتيكى گيرندههاى GABA در كونهاى انسان و موش صحرايى: ارزيابى قرابت خانوادگى

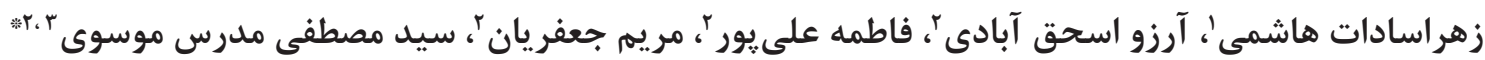

'دانشكده يزشكى، دانشعاه علوم يزشكى تهران، تهران، ايران

'مركز تحقيقات علوم اعصاب شفا، بيمارستان خاتم الانبياء، تهران، ايران

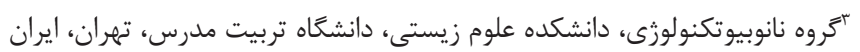

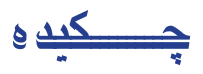

مقدمه: تلاش جهت ايجاد ارزشهاى فيلوزنتيك mRNA زيرواحدهاى اصلى گيرنده

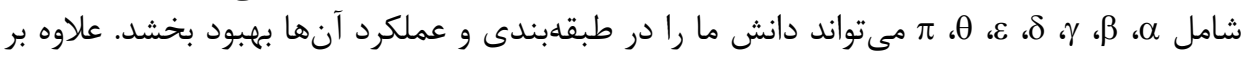

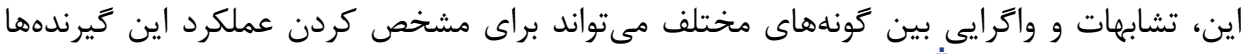

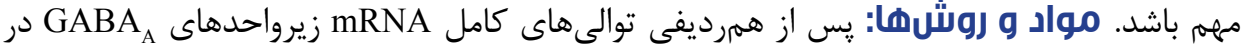

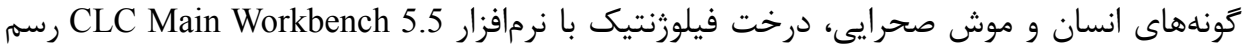
كرديد. يافتته

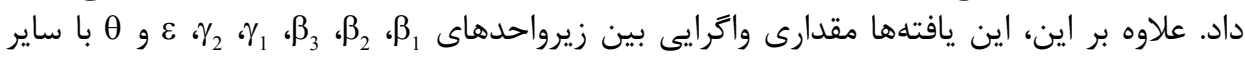

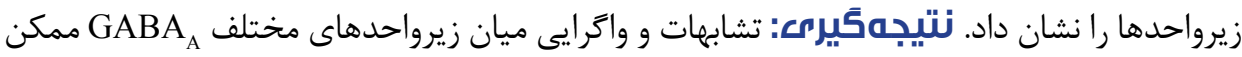

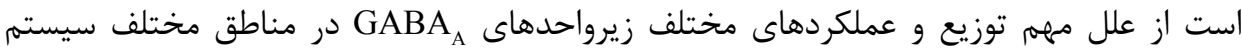
عصبى مركزى باشد.

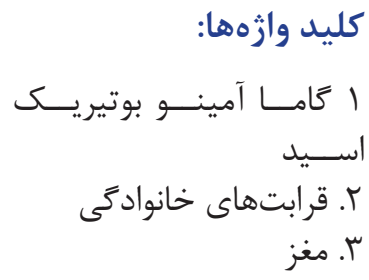

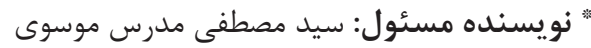
آدرس الكترونيكى: modarres.mousavi@gmail.com 
تنظيـهم يويــاى آنهــا بــه شـمار مى آيــد (9 9 9 9). ارتباط تيرندههاى GABA با بعضى اختلالات عصبى كمبــود كيرنــده GABA در انســان ســبـ ايجــاد اســتعداد

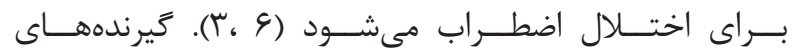
GABA

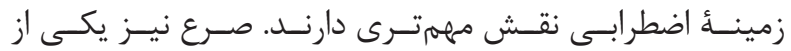

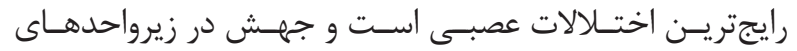

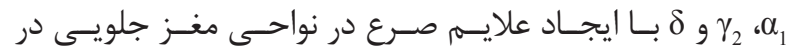

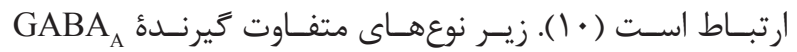

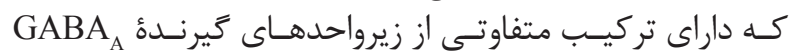

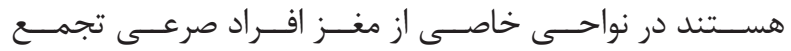

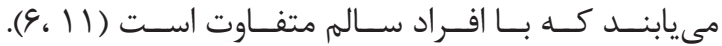

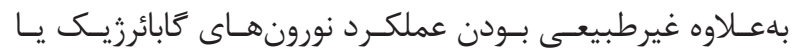

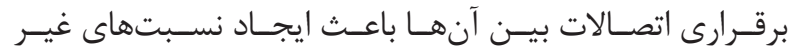

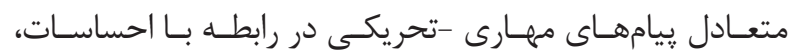

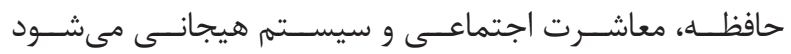

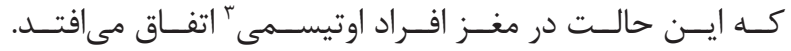

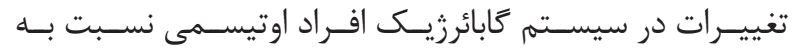

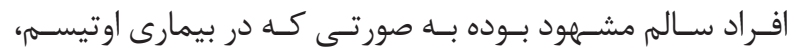

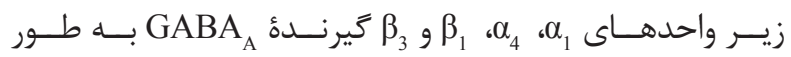

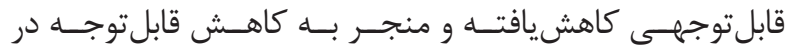

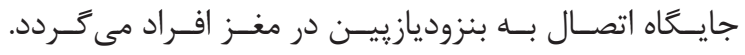

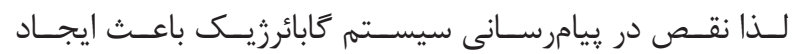

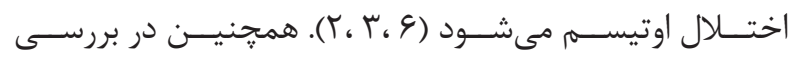

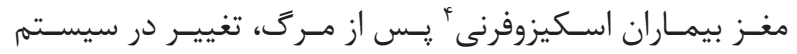

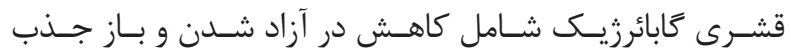

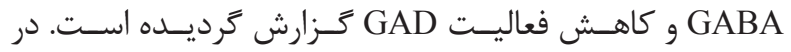

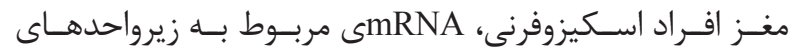

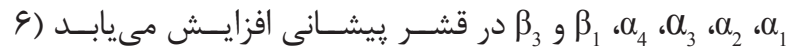

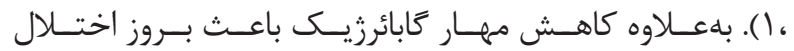

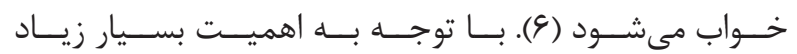

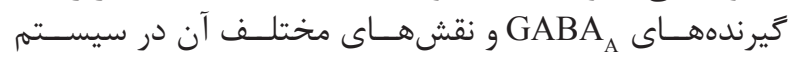

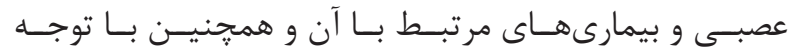

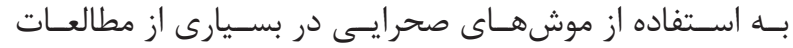

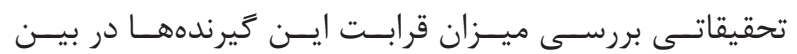

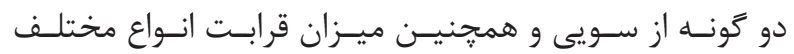

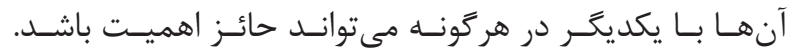

\section{مواد و روشها}

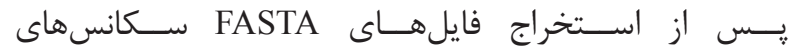

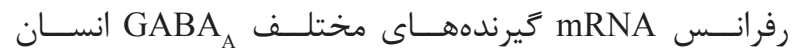

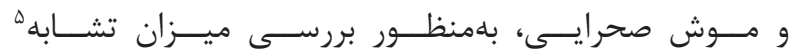

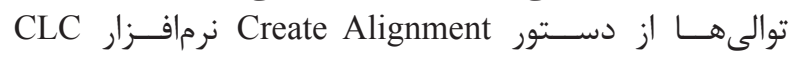
Main Workbench 5.5

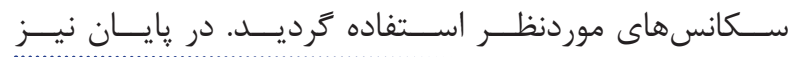

${ }^{1}$ Gamma-aminobutyric acid (GABA)

${ }^{2}$ Glutamic Acid Decarboxylase (GAD)

Autism
مقدمه

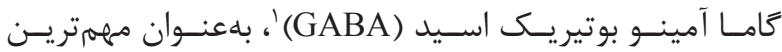

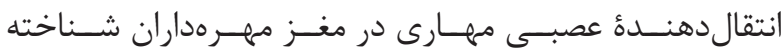

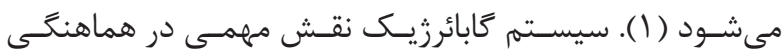

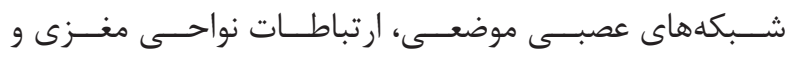

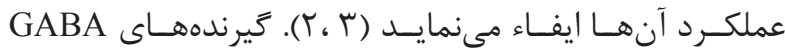

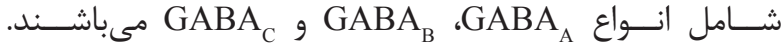

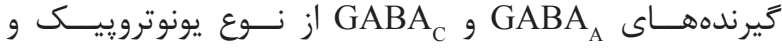

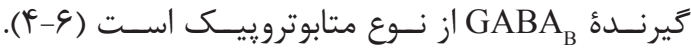

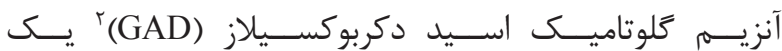

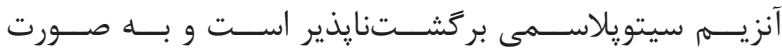

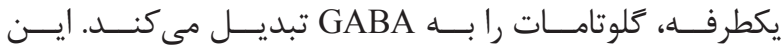

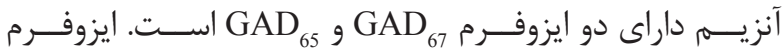
GAD GAD $_{67}$

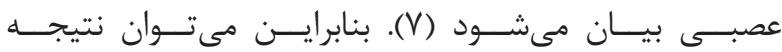
كرفـت كـــه ايزوفــــ

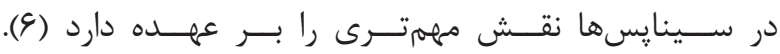

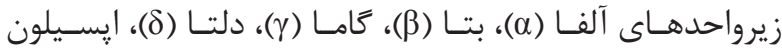

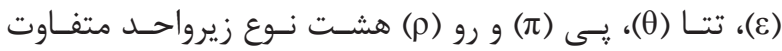
كيرنـده

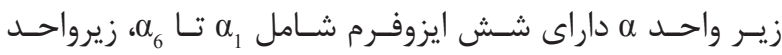

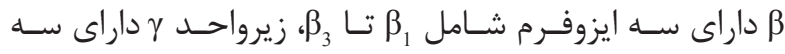

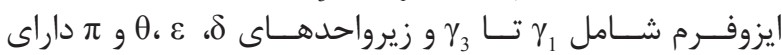

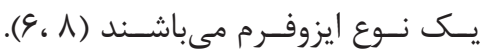

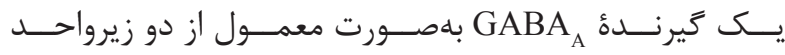

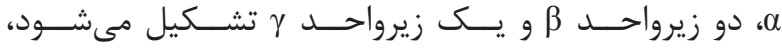

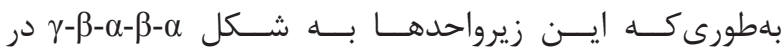

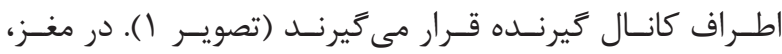

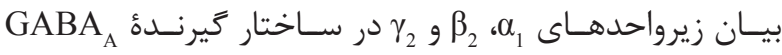

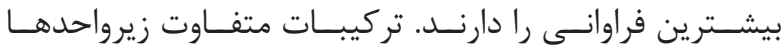

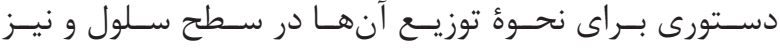

\section{$\mathrm{GABA}_{\mathrm{A}}$ receptor}

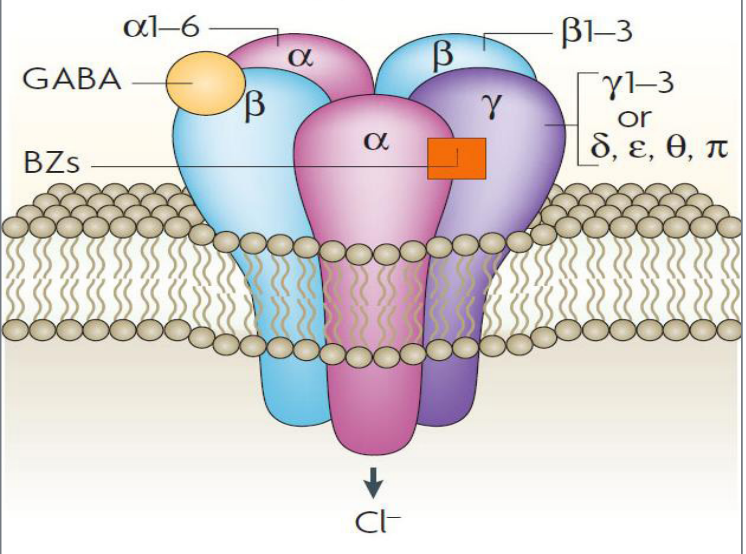

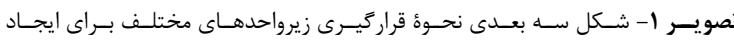

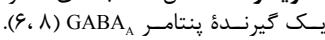

${ }^{4}$ Schizophrenia

${ }^{5}$ Similarities

${ }^{6}$ Alignment 


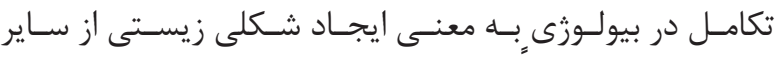

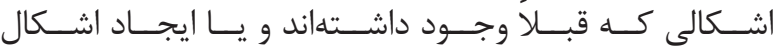

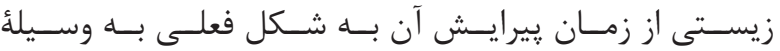

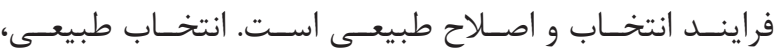

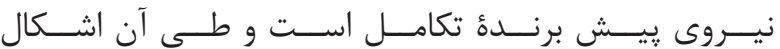

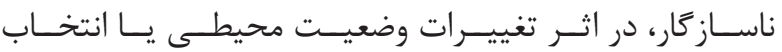

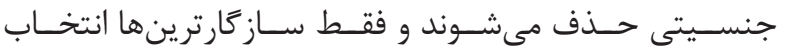

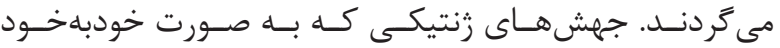

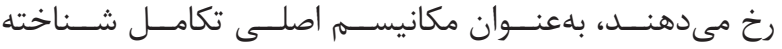

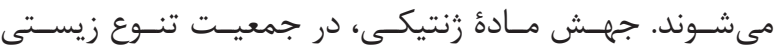

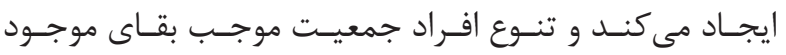

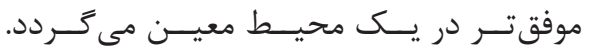

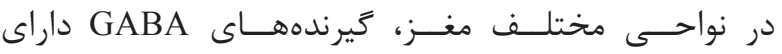

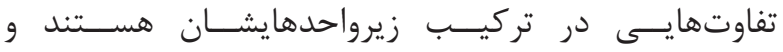

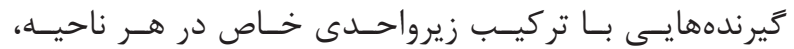

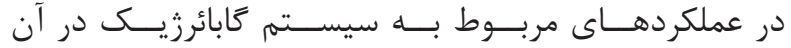

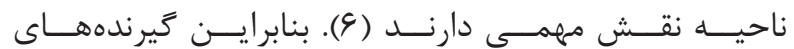
GABA

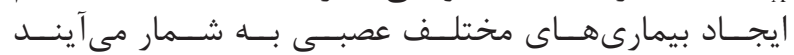

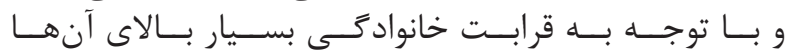

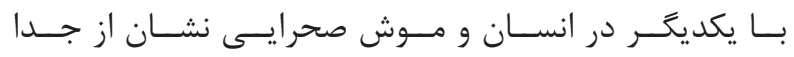

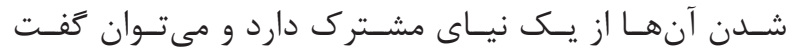

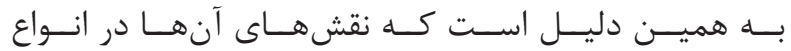

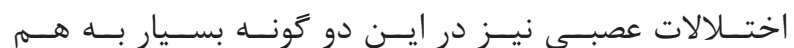

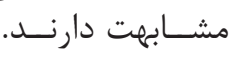

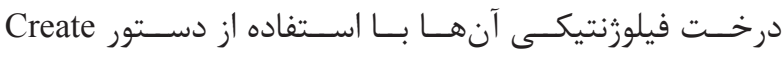

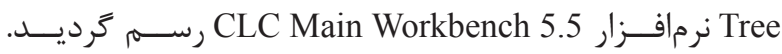

بافتهها

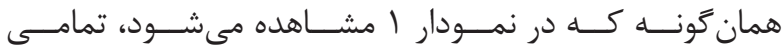

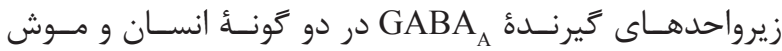

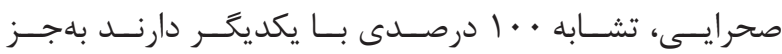

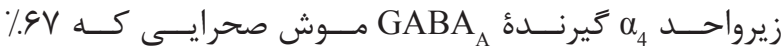

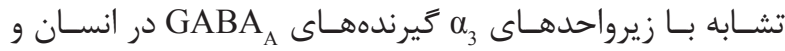

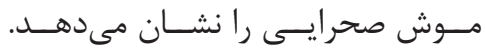

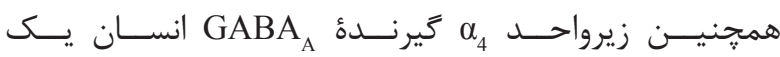

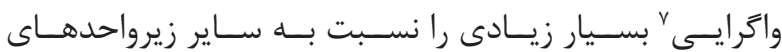

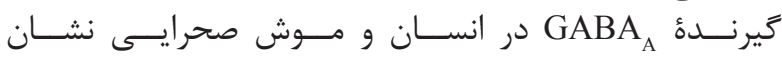

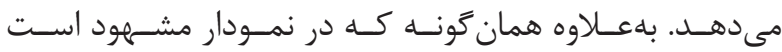

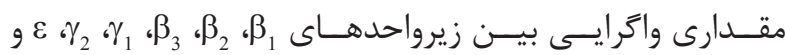

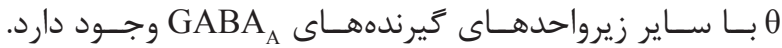

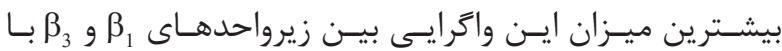

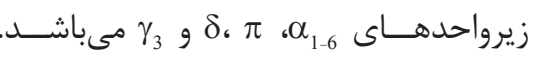

$$
\text { بحث و نتيجه كيرى }
$$

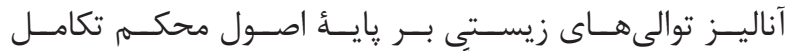

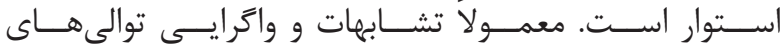

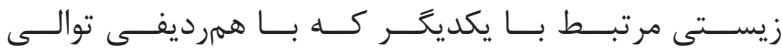

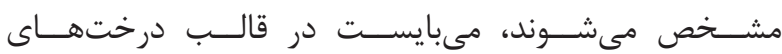

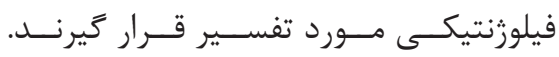

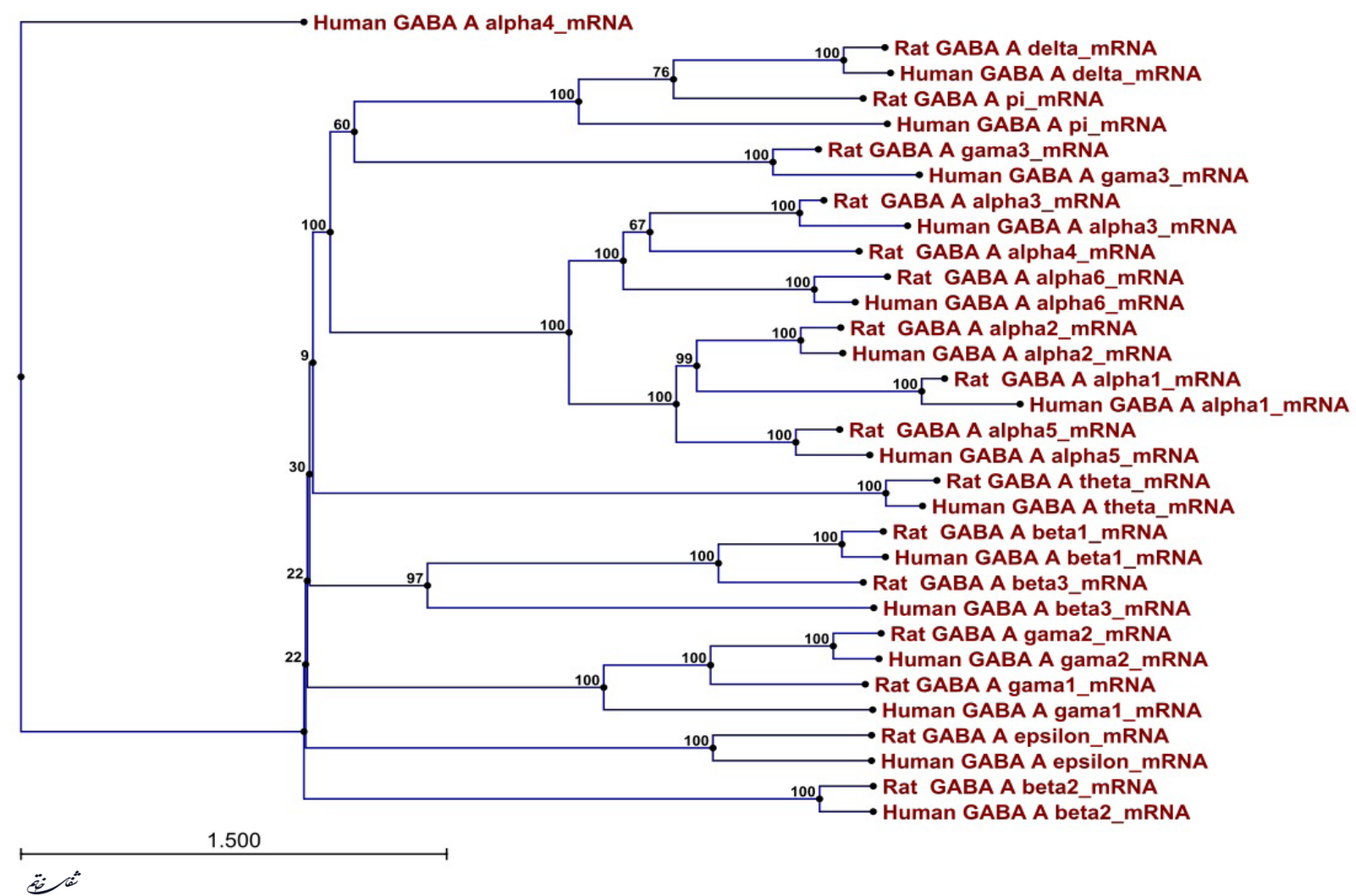

نمودار ا- درخت فيلوزنتيكى زيرواحدهاى مختلف GABA در دو كونة انسان و موش صحرايى؛ كه بيانكر ميزان تشابهات و واكرًايى زيرواحدهاى مختلف آنها با يكديكر مى باشد.

${ }^{7}$ Divergences 
1. Froestl W. An historical perspective on GABAergic drugs. Future Med Chem. 2011; 3: 163-75.

2. Rudolph U, Mohler H. GABAA receptor subtypes: Therapeutic potential in Down syndrome, affective disorders, schizophrenia, and autism. Annu Rev Pharmacol Toxicol. 2014; 54: 483-507.

3. Mohler H. GABAA receptors in central nervous system disease: anxiety, epilepsy, and insomnia. J Recept Signal Transduct Res. 2006; 26: 731-40.

4. Bormann J. The 'ABC' of GABA receptors. Trends Pharmacol Sci. 2000; 21: 16-9.

5. Olsen RW, Sieghart W. GABA A receptors: subtypes provide diversity of function and pharmacology. Neuropharmacology. 2009; 56: 141-8.

6. Rashidi A, Ahmadi S. Subunits of gamma-aminobutyric acid receptors and their roles in neuropsychological disorders. Shefaye Khatam. 2014; 2 (2) :70-80
7. Nasreen Z, Jameel T, Hasan A, Parveen N, Sadasivudu B. Glutamate decarboxylase and GABA aminotransferase levels in different regions of rat brain on the onset of Leptazol induced convulsions. Neurochem Res. 2012; 37: 202-4.

8. Jacob TC, Moss SJ, Jurd R. GABA(A) receptor trafficking and its role in the dynamic modulation of neuronal inhibition. Nat Rev Neurosci. 2008; 9: 331-43.

9. Farrant M, Nusser Z. Variations on an inhibitory theme: phasic and tonic activation of $\operatorname{GABA}(\mathrm{A})$ receptors. Nat Rev Neurosci. 2005; 6: 215-29.

10. Reid CA, Kullmann DM. GABAA receptor mutations in epilepsy (commentary on Lachance-Touchette et al.). Eur J Neurosci. 2011; 34: 235-6.

11. Drexel M, Kirchmair E, Sperk G. Changes in the expression of GABAA receptor subunit mRNAs in parahippocampal areas after kainic acid induced seizures. Front Neural Circuits. 2013; 7: 1-13. 